\title{
Pengembangan Model Pembelajaran Adaptive Berdasarkan Teori Kecerdasan Majemuk
}

\author{
Muhammad Qomarudin ${ }^{1 *}$, Mustafa ${ }^{2}$, Mochamad Abdul Basir ${ }^{3}$ \\ ${ }^{1,2,3}$ Universitas Islam Sultan Agung Semarang, Semarang \\ *mqomaruddin@unissula.ac.id
}

\begin{abstract}
Each child has different potentials or talents, to optimize talent into achievement needs education and training programs, opportunities, facilities and infrastructure to support from family so that the potential is not only a hidden talent. The source of one's intelligence is the habit of making new products that have cultural value (creativity) and their habit of solving problems independently. Adaptive Learning is a system that supports learning adapted to the capabilities and learning styles of students. Personalization of learning content based on data analysis habits of student learning activities give a significant effect on the achievement of learning objectives. Through the Adaptive Learning model, students will learn to be tailored to their individual student profiles, educational background, competency level, learning style and basic skills as they begin learning. Result of research through survey and indept interview to teacher obtained 87,3\% responder say important every lesson make Lesson plan. Furthermore, $74 \%$ respondents said that in the preparation of Lesson Plan is important to be adjusted to the student profile. and 93,6\% respondents agree that each child has a different profile and learning style. Student profile in this research is done through observation to the habits that children do every day. In addition to the students 'profiles based on the theory of multiple intelligences, other things required by the teacher as a reference for the preparation of the lesson plan include students' family background, previous learning outcomes, hobbies, portfolios and student learning styles. Through the process of observation of daily activities of students will be obtained profiles of students based on the theory of multiple intelligences, furthermore by clustering method can be seen profile group of students which further became the reference of the preparation of Lesson Plan.
\end{abstract}

Keywords: Multiple Intelligence, Learning Model, the Student Profille, Clustering, Learning Style

\begin{abstract}
Abstrak
Setiap anak memiliki potensi atau bakat yang berbeda, untuk mengoptimalkan bakat menjadi prestasi perlu program pendidikan dan latihan, kesempatan, sarana dan prasarana hingga dukungan dari keluarga sehingga potensi tersebut tidak hanya menjadi bakat terpendam. Sumber kecerdasan seseorang adalah kebiasaannya untuk membuat produk-produk baru yang punya nilai budaya (kreativitas) dan kebiasaannya menyelesaikan masalah-masalah secara mandiri. Personalisasi konten pembelajaran berdasarkan analisa data kebiasaan aktivitas belajar siswa memberikan efek yang signifikan terhadap pencapaian tujuan pembelajaran. Hasil penelitian melalui survey dan indept interview terhadap guru diperoleh $87,3 \%$ responden mengatakan penting setiap pembelajaran menyusun Lesson plan. Selanjutnya $74 \%$ responden mengatakan bahwa dalam penyusunan Lesson Plan penting disesuaikan dengan profil siswa. dan 93,6\% responden setuju bahwa setiap anak memiliki profil dan gaya belajar yang berbeda-beda. Profil siswa dalam penelitian ini dilakukan melalui observasi terhadap kebiasaan yang dilakukan anak setiap hari. Selain profil siswa berdasarkan teori kecerdasan majemuk, hal lain yang dibutuhkan oleh guru sebagai referensi penyusunan lesson plan diantaranya latar belakang keluarga siswa, hasil pembelajaran sebelumnya, Hobi, portofolio dan gaya belajar siswa. Melalui proses observasi kegiatan harian siswa akan didapatkan profil siswa berdasarkan teori kecerdasan majemuk, selanjutnya dengan metode klustering dapat dilihat profil kelompok siswa yang selanjutnya menjadi acuan penyusunan Lesson Plan.
\end{abstract}

Kata kunci: Kecerdasan majemuk, Model Pembelajaran, Profil siswa, Klustering, Gaya Belajar 


\section{Pendahuluan}

Pembelajaran yang saat ini berjalan di sebagian besar sekolah adalah seorang guru menyampaikan pembelajaran menggunakan strategi pembelajaran yang sudah dikuasai tanpa memahami bahwa setiap siswa ataupun sekelompok siswa dalam kelas memiliki kecenderungan gaya belajar yang berbedabeda. Padahal setiap anak memiliki potensi atau bakat yang berbeda-beda dan untuk mengoptimalkan bakat tersebut hingga menjadi prestasi sangat dipengaruhi oleh stimulasi orang lain, kondisi lingkungan sekitar. Potensi akan berkembang jika bertemu dengan program pendidikan dan latihan, kesempatan, sarana dan prasarana hingga dukungan dari orang tua atau keluarga sehingga potensi tersebut tidak hanya menjadi bakat terpendam (Munandar, 1999).

Dalam UU RI. No. 20 tahun 2003 tentang Sistem Pendidikan Nasional yang tercantum pada Bab I pasal 1 telah disebutkan dengan jelas, bahwa Pendidikan Nasional adalah terbentuknya suasana pembelajaran yang dapat mengembangkan potensi peserta didik (Deperindag, 2009).

Teori kecerdasan majemuk mengambarkan kecerdasan dengan perspektif yang lebih luas dan pragmatis sehingga kecerdasan tidak dipandang sekedar konsep yang abstrak namun lebih bermakna fungsional yang dapat terlihat dalam perilaku sehari-hari dengan beragam cara yang lebih komprehensif mencakup delapan kecerdasan, yakni linguistik, logis-matematis, spasial, kinestetis, musikal, interpersonal, intrapersonal, naturalis (Amstrong, 2002). Sumber kecerdasan seseorang adalah kebiasaannya untuk membuat produk-produk baru yang punya nilai budaya (kreativitas) dan kebiasaannya menyelesaikan masalah-masalah secara mandiri (Problem Solving)(Chatib, 2011).

Teori kecerdasan majemuk dapat digunakan sebagai dasar penilai potensi kecerdasan anak, hasil atau profile multiple intelligence akan sangat berguna untuk bimbingan dan pendidikan. Walaupun belum ada prosedur yang sudah ditentukan secara eksplisit untuk mengembangkan profil kecerdasan majemuk namun Gardner meyakini bahwa kompetensi intelektual anak dapat diidentifikasi melalui observasi (Chatib, 2011). Tidak ada satupun "test tercanggih" di masyarakat yang dapat menghasilkan survey yang komprehensif mengenai kecerdasan manjemuk siswa. Ini tidak berarti bahwa test formal tidak dapat memberikan informasi mengenai kecerdasan siswa; seperti yang nantinya akan saya bahas, test formal dapat memberikan gambaran tentang berbagai kecerdasan. Walaupun demikian, satu-satunya alat terbaik untuk menilai kecerdasan majemuk (Multiple Intelligences) siswa, 
mungkin adalah yang sudah selalu tersedia selama ini : Observasi Sederhana. (Amstrong, 2002).

Dalam pengembangan alat ukur Multiple Intelligences berbasis komputer suatu model penelusuran minat dan bakat siswa SMA didapatkan bahwa dengan adanya alat ukur berbasis komputer tersebut dapat mempercepat proses penelusuran minat dan bakat siswa SMA menggunakan metode multiple intelligences (Setiawati, 2008).

Beberapa sekolah sudah menerapkan pembelajaran yang diorientasikan pada potensi kecerdasan anak namun hingga saat ini belum ada aplikasi computer base untuk mempermudah dan mempercepat proses identifikasi potensi kecerdasan siswa. Apalagi pada dasarnya potensi kecerdasan anak tidaknya statis hanya dapat dilihat dari satu kali proses identifikasi namun perlu dilakukan secara bertahap dengan rentang waktu minimal setiap 6 bulan. Oleh karena itu, sangat diperlukan sebuah sistem informasi manajemen untuk proses identifikasi potensi kecerdasan anak hingga manajemen pengelolaan data yang sudah didapatkan sehingga dapat dilakukan analisis lebih lanjut pada proses identidikasi potensi anak pada tahap selanjutnya.

Adaptive Learning adalah sistem yang mendukung pembelajaran yang disesuaikan dengan kapabilitas dan gaya belajar siswa.
Personalisasi

konten

pembelajaran berdasarkan analisa data kebiasaan aktivitas belajar siswa memberikan efek yang signifikan terhadap pencapaian tujuan pembelajaran (Setiawati, 2008). Melalui model Adaptive Learning maka siswa akan belajar disesuaikan dengan profil individu siswa, latar belakang pendidikan, level kompetensi, gaya belajar dan kemampuan dasar saat akan memulai belajar (Setiawati, 2008).

\section{Metoda Penelitian}

\subsection{Populasi dan Sampel}

Populasi dalam penelitian ini adalah guru di SD, SMP dan SMK di Jawa Tengah dengan pilihan di kota Semarang, Kudus, Pekalongan, Salatiga dan Solo. Dalam penelitian ini terdapat 173 responden guru di lima kota dengan distribusi sebanyak 53 responden $(30,6 \%)$ dari Semarang, 26 responden $(15,0 \%)$ dari Kudus, 25 responden $(14,5 \%)$ dari Pekalongan, 31 responden $(17,9 \%)$ dari Salatiga dan 38 responden $(22,0 \%)$ dari Solo.

\subsection{Jenis Data}

Data yang digunakan dalam penelitian ini adalah data primer dan data sekunder. Data primer di peroleh melalui penyebaran kuesioner dan melakukan wawancara mendalam di kota Semarang, Kudus, Pekalongan, Salatiga dan Solo. Data sekunder meliputi data-data penyusunan lesson plan 
dan data-data lain yang terkait dengan penelitian ini.

\subsection{Analisis Data}

Pengambilan data melalui isian kuesioner dan wawancara mendalam dengan guru dan stakeholder terkait yang dalam penelitian ini. Analisis penelitian ini menggunakan analisis deskriptif baik dari analisa data primer maupun sekunder.

\section{Hasil dan Pembahasan}

\subsection{Profil Responden}

Profil responden untuk penelitian pengembangan model pembelajaran adaptive berdasarkan teori kecerdasan majemuk dantaranya:

\section{a. Profil responden berdasarkan asal kota}

Berdasarkan asal kota responden dalam penelitian ini ditunjukan yang paling besar dari Kota Semarang dengan jumlah responden sebanyak 53 orang $(30,6 \%)$. Secara lengkap profil responden berdasarkan asal kota ditunjukan pada Tabel 1 dan Gambar 1.

\begin{tabular}{clrc}
\multicolumn{4}{c}{ Tabel 1. Profil responden berdasarkan asal kota } \\
\hline No & \multicolumn{1}{c}{ Kota } & Jumlah & Prosentase \\
\hline 1 & Semarang & 53 & $30,6 \%$ \\
2 & Salatiga & 31 & $17,9 \%$ \\
3 & Solo & 38 & $22,0 \%$ \\
4 & Pekalongan & 25 & $14,5 \%$ \\
5 & Kudus & 26 & $15,0 \%$ \\
\hline & Total & 173 & \\
\hline
\end{tabular}

\section{b. Profil responden berdasarkan Jenis Kelamin}

Berdasarkan jenis kelamin, profil responden pada penelitian ini lebih dominan dengan jenis kelamin laki-laki yaitu mencapai 111 orang ( 64,2\%). Data profil responden berdasarkan jenis kelamin ditunjukan pada Tabel 2 dan grafiknya pada Gambar 2.

Tabel 2. Profil responden berdasarkan Jenis Kelamin

\begin{tabular}{clrc}
\hline No & Jenis Kelamin & Jumlah & Prosentase \\
\hline 1 & Laki-Laki & 111 & $64,2 \%$ \\
2 & Perempuan & 62 & $35,8 \%$ \\
\hline & Total & 173 & \\
\hline
\end{tabular}




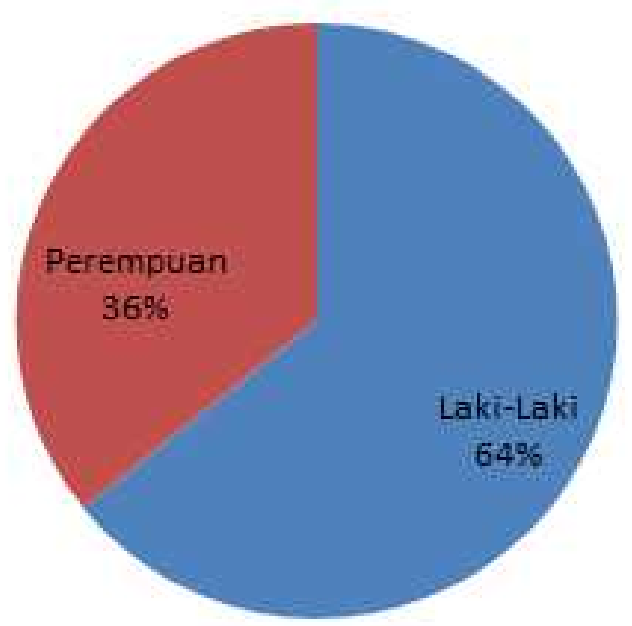

Gambar 2. Profil responden berdasarkan Jenis Kelamin

\section{c. Profil Responden Berdasarkan Usia}

Berdasarkan usia, profil responden pada penelitian ini lebih dominan dengan usia 35 s/d 44 tahun ( 42,8\%). Data profil responden berdasarkan jenis kelamin ditunjukan pada Tabel 2 dan grafiknya pada Gambar 2. Berdasarkan data pada Tabel 3 dan gambar 3 dapat juga dikalkulasi bahwa responden pada penelitian ini sangat sesuai dengan tujuan besar penelitian yaitu responden dengan usia 24 s/d 44 tahun mencapai 118 orang (68,2\%) yaitu para guru yang memang memahami bagaimana mengoptimalkan teknologi informasi dan komunikasi untuk mendukung pembelajaran.

Tabel 3. Profil responden berdasarkan Usia

\begin{tabular}{clrc}
\hline No & Rentang Usia & \multicolumn{1}{c}{ Jumlah } & Prosentase \\
\hline 1 & 18-23 Tahun & 4 & $2,3 \%$ \\
2 & 24-34 Tahun & 44 & $25,4 \%$ \\
3 & 35-44 Tahun & 74 & $42,8 \%$ \\
4 & 45 - 54 Tahun & 51 & $29,5 \%$ \\
\hline & Total & 173 & \\
\hline
\end{tabular}

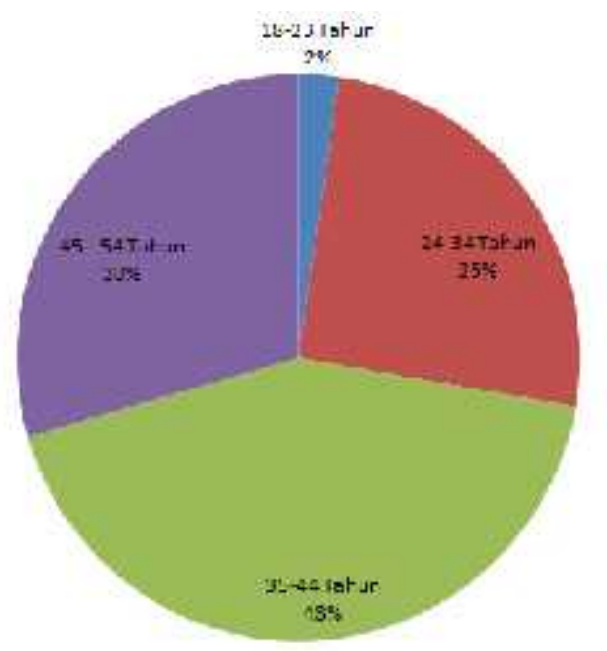

Gambar 3. Profil responden berdasarkan Usia

d. Profil Responden Berdasarkan asal

\section{lembaga pendidikan}

Berdasarkan asal lembaga pendidikan, jenjang pendidikan responden kita pilih dari SD, SMP dan SMA/K. Profil responden berdasarkan asal lembaga pendidikan ditunjukan pada Tabel 4. dan Gambar 4.

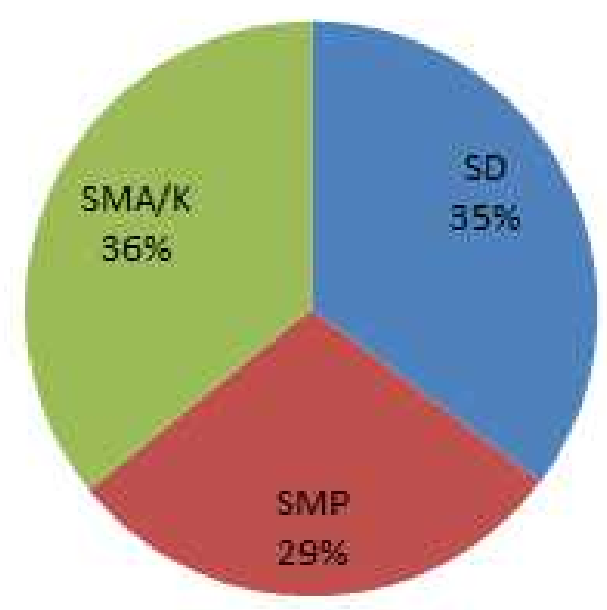

Gambar 4. Profil responden berdasarkan jenjang lembaga pendidikan 
3.2. Profil Siswa, Lesson Plan dan Strategi Pembelajaran

Teori kecerdasan majemuk dapat digunakan sebagai dasar penilai potensi kecerdasan anak. Hasil atau profil kecerdasan majemuk akan sangat berguna untuk bimbingan dan pendidikan. Walaupun belum ada prosedur yang sudah ditentukan secara eksplisit untuk mengembangkan profil kecerdasan majemuk namun Gardner meyakini bahwa kompetensi intelektual anak dapat diidentifikasi melalui observasi, (Sattler, h.53)

Tidak ada satupun "test tercanggih" di masyarakat yang dapat menghasilkan survey yang komprehensif mengenai kecerdasan manjemuk siswa. Ini tidak berarti bahwa test formal tidak dapat memberikan informasi mengenai kecerdasan siswa; seperti yang nantinya akan saya bahas, test formal dapat memberikan gambaran tentang berbagai kecerdasan. Walaupun demikian, satu-satunya alat terbaik untuk menilai kecerdasan majemuk (Multiple Intelligences) siswa, mungkin adalah yang sudah selalu tersedia selama ini : Observasi Sederhana. (Amstrong, 2002).

\section{a. Profil Siswa}

Dalam menyusun strategi pembelajaran, seorang guru perlu mengetahui profil siswa yang diantaranya meliputi Latar belakang keluarga, hobi dan karya/portofolio. Pentingnya profil siswa terhadap penentuan strategi pembelajaran ditunjukan pada Tabel 5 dan Gambar 5. Hasil penelitian menunjukan bahwa sebanyak 151 orang $(87,3 \%)$ mengatakan bahwa profil siswa penting dipahami para guru sebagai referensi untuk menentukan strategi pembelajaran di kelas.

Tabel 5. Tingkat kepentingan profil siswa terhadap penentuan strategi pembelajaran

\begin{tabular}{clrc}
\hline No & \multicolumn{1}{c}{ Uraian } & Jumlah & Prosentase \\
\hline 1 & Sangat Penting & 96 & $55,5 \%$ \\
2 & Penting & 55 & $31,8 \%$ \\
3 & Kurang Penting & 21 & $12,1 \%$ \\
4 & Tidak Penting & 1 & $0,6 \%$ \\
& Sangat Tidak & & \\
5 & Penting & 0 & $0,0 \%$ \\
\hline & Total & 173 & \\
\hline
\end{tabular}

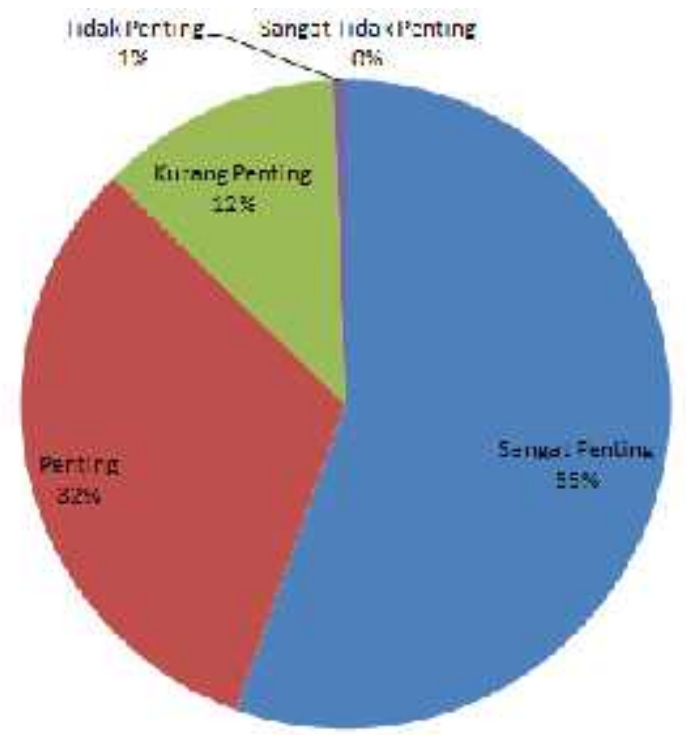

Gambar 5. Tingkat kepentingan profil siswa terhadap penentuan strategi pembelajaran

Profil siswa yang perlu diketahui oleh guru sebelum memulai pembelajaran berdasarkan hasil penelitian ditunjukan oleh Tabel 6 dan Gambar 6. 
Tabel 6. Kebutuhan profil siswa untuk penentuan strategi pembelajaran

\begin{tabular}{clrr}
\hline No & \multicolumn{1}{c}{ Referensi untuk pembelajaran } & Jumlah \\
\hline 1 & Latar belakang keluarga siswa & 157 \\
2 & Hobi siswa & 132 \\
3 & Hasil karya yang pernah dibuat siswa & 125 \\
& $\begin{array}{l}\text { (Portofolio) } \\
4\end{array}$ & Hasil pembelajaran di kelas & 148 \\
& sebelumnya & & 124 \\
5 & Gaya Belajar siswa & & 109 \\
6 & Permasalahan-permasalahan & siswa & \\
& tahun sebelumnya & & 64 \\
7 & Sikap/attitude siswa & & 6 \\
\hline
\end{tabular}

\section{b. Gaya Belajar}

Dalam penelitian ini setiap responden diminta memberikan persetujuan terkait dengan kondisi pentingnya profile siswa dan penyusunan lesson plan. Hasil penelitian ditunjukan pada data sebagai berikut:

- Setiap anak adalah unik, memiliki profil dan gaya belajar yang berbeda-beda

Tabel 7 Pendapat Responden terkait setiap anak memiliki profil dan gaya belajar yang berbeda-beda

\begin{tabular}{clrr}
\hline No & Uraian & Jumlah & Prosentase \\
\hline 1 & Sangat Setuju & 103 & $59,5 \%$ \\
2 & Setuju & 59 & $34,1 \%$ \\
3 & Netral & 7 & $4,0 \%$ \\
4 & Tidak Setuju & 0 & $0,0 \%$ \\
& Sangat Tidak & & \\
5 & Setuju & 4 & $2,3 \%$ \\
& & 173 & \\
\hline
\end{tabular}

- Pembuatan profil siswa dapat dilakukan melalui observasi kegiatan keseharian yang paling disenangi siswa. Sebagimana dipaparkan pada Tabel 8 berikut.
Tabel 8. Pendapat responden terkait profil siswa bisa disusun melalui kegiatan observasi

\begin{tabular}{rlrr}
\hline No & Uraian & Jumlah & Prosentase \\
\hline 1 & Sangat Setuju & 51 & $29,5 \%$ \\
2 & Setuju & 98 & $56,6 \%$ \\
3 & Netral & 20 & $11,6 \%$ \\
4 & Tidak Setuju & 3 & $1,7 \%$ \\
& Sangat Tidak & & \\
5 & Setuju & 1 & $0,6 \%$ \\
& & 173 & \\
\hline
\end{tabular}

- Portofolio hasil karya siswa dapat digunakan sebagai referensi pembuatan profil siswa, sebaimana dipaparkan pada Tabel 9.

Tabel 9. Pendapat responden terkait portofolio siswa bisa dijadikan referensi profil siswa

\begin{tabular}{rlrr}
\hline No & \multicolumn{1}{c}{ Uraian } & Jumlah & Prosentase \\
\hline 1 & Sangat Setuju & 50 & $28,9 \%$ \\
2 & Setuju & 97 & $56,1 \%$ \\
3 & Netral & 20 & $11,6 \%$ \\
4 & Tidak Setuju & 3 & $1,7 \%$ \\
& Sangat Tidak & & $1,7 \%$ \\
5 & Setuju & 3 &
\end{tabular}

173

- Tabel 10 menjelaskan Informasi profil dan gaya belajar siswa sangat dibutuhkan untuk penyusunan lesson plan dan strategi pembelajaran

Tabel 10. Pendapat responden terkait kebutuhan profil siswa untuk penyusunan lesson plan

\begin{tabular}{rlrr}
\hline No & \multicolumn{1}{c}{ Uraian } & Jumlah & Prosentase \\
\hline 1 & Sangat Setuju & 64 & $37,0 \%$ \\
2 & Setuju & 95 & $54,9 \%$ \\
3 & Netral & 11 & $6,4 \%$ \\
4 & Tidak Setuju & 3 & $1,7 \%$ \\
& Sangat Tidak & & $0,0 \%$ \\
5 & Setuju & 0 &
\end{tabular}

173

- Lesson Plan sangat penting disusun sebelum memulai pembelajaran (lihat Tabel 11). 
Tabel 11. Pendapat responden terkait pentingnya Lesson Plan

\begin{tabular}{rlrr}
\hline No & Uraian & Jumlah & Prosentase \\
\hline 1 & Sangat Setuju & 97 & $56,1 \%$ \\
2 & Setuju & 65 & $37,6 \%$ \\
3 & Netral & 10 & $5,8 \%$ \\
4 & Tidak Setuju & 1 & $0,6 \%$ \\
& Sangat Tidak & & $0,0 \%$ \\
5 & Setuju & 0 & \\
& & 173 & \\
\hline
\end{tabular}

\section{c. Penggunaan Strategi Pembelajaran}

Penggunaan strategi perlu disesuaikan dengan gaya belajar / profil siswa (Pendapat responden lihat Tabel 12)

Tabel 12. Pendapat responden terkait perlu penyesuaian strategi pembelajaran dengan gaya belajar/profil siswa.

\begin{tabular}{rlrr}
\hline No & \multicolumn{1}{c}{ Uraian } & Jumlah & Prosentase \\
\hline 1 & Sangat Setuju & 77 & $44,5 \%$ \\
2 & Setuju & 82 & $47,4 \%$ \\
3 & Netral & 12 & $6,9 \%$ \\
4 & Tidak Setuju & 1 & $0,6 \%$ \\
& Sangat Tidak & & \\
5 & Setuju & 1 & $0,6 \%$ \\
& & 173 & \\
\hline
\end{tabular}

\section{Kesimpulan}

Berdasarkan progres penelitian ini dapat disimpulkan sebagai berikut:

1. Untuk mendukung pembelajaran sebagian besar guru yang menjadi responden dalam penelitian ini menyampaikan pentingnya profil siswa dikaitkan dengan penyusunan lesson plan.

2. Strategi pembelajaran perlu dilakukan penyesuaian berdasarkan profil siswa yang bisa didapatkan dari proses observiasi kegiatan harian, portofolio dan latar belakang keluarga siswa.

3. Profil kecerdasan majemuk siswa dapat dilakukan melalui obervasi kegiatan harian siswa melalui isian kuesioner dengan skala likert.

\section{Saran}

1. Desain system yang akan dibuat disesuaikan dengan kebutuhan guru dan sekolah sehingga perlu dilakukan desain yang fleksibel seperti kebutuhan untuk lesson plan, pelaksanaan dan evaluasi pembelajaran

2. Perlu ada penyamaan persepsi dalam hal pengelolaan Learning Management System baik disekolah negeri maupun swasta

\section{Daftar Pustaka}

Amstrong, T. (2002). Sekolah Para Juara. Bandung: Kaifa.

Chatib, M. (2011). Gurunya Manusia. Bandung: Kaifa.

Deperindag, D. P. R. I. Pengembangan Ekonomi Kreatif Indonesia 2025: Rencana Pengembangan Ekonomi Kreatif Indonesia 2009-2015 (2009).

Munandar, U. (1999). Mengembangkan Bakat dan Kreativitas Anak Sekolah-Petunjuk bagi para Guru dan Orang Tua. Jakarta: Gramedia Widiasarana Indonesia.

Setiawati, F. A. (2008). Pengembangan alat ukur Multiple Intelligences berbasis komputer suatu model penelusuran minat dan bakat siswa SMA. Jurnal Psikologi Pendidikan Dan Bimbingan UNY., 38(1). 